\title{
Contralateral Prophylactic Mastectomy (CPM) Consensus Statement from the American Society of Breast Surgeons: Data on CPM Outcomes and Risks
}

\author{
Judy C. Boughey, MD ${ }^{1}$, Deanna J. Attai, $\mathrm{MD}^{2}$, Steven L. Chen, MD, MBA ${ }^{3}$, Hiram S. Cody, $\mathrm{MD}^{4}$, Jill R. Dietz, MD ${ }^{5}$, \\ Sheldon M. Feldman, $\mathrm{MD}^{6}$, Caprice C. Greenberg, MD, MPH ${ }^{7}$, Rena B. Kass, $\mathrm{MD}^{8}$, Jeffrey Landercasper, $\mathrm{MD}^{9}$, \\ Valerie Lemaine, MD, MPH ${ }^{1}$, Fiona MacNeill, MB, BS ${ }^{10}$, David H. Song, MD ${ }^{11}$, Alicia C. Staley, BS, MBA, MS $^{12}$, \\ Lee G. Wilke, MD ${ }^{7}$, Shawna C. Willey, $\mathrm{MD}^{13}$, Katharine A. Yao, $\mathrm{MD}^{14}$, and Julie A. Margenthaler, MD ${ }^{15}$ \\ ${ }^{1}$ Department of Surgery, Mayo Clinic, Rochester, MN; ${ }^{2}$ Department of Surgery, David Geffen School of Medicine at \\ UCLA, UCLA Health Burbank Breast Care, Burbank, CA; ${ }^{3}$ Department of Surgery, OasisMD, San Diego, CA; \\ ${ }^{4}$ Department of Surgery, Memorial Sloan Kettering Cancer Center, New York, NY; ${ }^{5}$ Department of Surgery, Case Western \\ Reserve School of Medicine, Seidman Cancer Center, Cleveland, OH; ${ }^{6}$ Department of Surgery, Columbia University, New \\ York, NY; ${ }^{7}$ Department of Surgery, University of Wisconsin, Madison, WI; ${ }^{8}$ Department of Surgery, College of Medicine, \\ The Pennsylvania State University, Hershey, PA; ${ }^{9}$ Department of Surgery, Gundersen Health System, Lacrosse, WI; \\ ${ }^{10}$ Department of Surgery, Royal Marsden Hospital, London, UK; ${ }^{11}$ Department of Surgery, University of Chicago, \\ Chicago, IL; ${ }^{12}$ Akari Healthcare, Charleston, MA; ${ }^{13}$ Department of Surgery, Medstar Georgetown University Hospital, \\ Washington, DC; ${ }^{14}$ Department of Surgery, NorthShore University Health System, Evanston, IL; ${ }^{15}$ Department of Surgery, \\ Center for Advanced Medicine, Breast Health Center, St. Louis, MO
}

The American Society of Breast Surgeons (ASBrS) endorses the American Board of Internal Medicine's Choosing Wisely campaign statement: "Don't routinely perform a double mastectomy in patients who have a single breast with cancer." ${ }^{1}$ However, women with a newly diagnosed unilateral breast cancer are increasingly opting for bilateral mastectomy. This has been seen in patients who are candidates for breast conservation who elect mastectomy as well as those requiring mastectomy for their index breast cancer. ${ }^{2}$ National rates of contralateral prophylactic mastectomy (CPM) in the United States have been increasing and this trend is continuing. ${ }^{2-4}$

There has been significant controversy surrounding this topic, and it has received attention from national societies as well as the media. Therefore, the ASBrS convened a panel of experts to develop a consensus statement on CPM. Initial

(C) The Author(s) 2016. This article is published with open access at Springerlink.com

First Received: 16 May 2016; Published Online: 28 July 2016

J. C. Boughey, MD

e-mail: boughey.judy@mayo.edu literature review was performed and exchanged electronically by the panel, followed by an in-person meeting of the consensus group and polling of the membership of the ASBrS at the 2016 annual meeting. The consensus statement consists of two parts. This paper, part 1, outlines the data on the impact of $\mathrm{CPM}$ on cancer and noncancer outcomes, including risks of CPM and when CPM should be considered or discouraged. Part 2 outlines whether CPM utilization should be a quality measure, role of sentinel node biopsy for CPM, perspectives on CPM from patients and from providers in other countries, and counseling considerations for patients desiring CPM and includes a discussion template for providers to use with patients regarding CPM. The ASBrS Executive Committee reviewed and approved the statement. This consensus statement was developed to guide patient and physician discussion and should not affect insurance coverage.

The consensus group agreed that CPM should be discouraged for an average-risk woman with unilateral breast cancer. However, patient's values, goals, and preferences should be included to optimize shared decision making when discussing CPM. The final decision whether or not to proceed with CPM is a result of the balance between benefits and risks of CPM and patient preference. 


\section{BREAST CONSERVATION OR MASTECTOMY}

The consensus group recommends consideration of breast conservation for all patients who are appropriate candidates. Breast conservation is equivalent to mastectomy in survival outcome and has been the preferred treatment for early-stage breast cancer since the National Cancer Institute statement in $1991 .^{5}$ Neoadjuvant chemotherapy and neoadjuvant endocrine therapy are highly successful in providing tumor size reduction to increase breast conservation rates, and oncoplastic approaches allow resection of larger tumors with reshaping and provide an excellent cosmetic outcome. ${ }^{6-9}$ Increase in use of breast conservation can decrease CPM rates. Complication rates have been shown to be lower with breastconserving surgery and adjuvant radiation than with mastectomy and reconstruction. ${ }^{10}$

\section{Summary}

The panel recommends advocating for breast conservation for all appropriately eligible patients and considering neoadjuvant systemic therapy and/or oncoplastic approaches to facilitate breast conservation where possible.

\section{CONTRALATERAL PROPHYLACTIC MASTECTOMY}

For women who elect or require mastectomy for management of their index breast cancer, the option of removing the contralateral breast is often discussed. Multiple factors should be considered including family history, patient age, comorbidities, and tumor prognosis, as well as the initial plan for surgery, systemic therapy, and radiotherapy. The surgical consultation should include a detailed discussion of local treatment options, the risk of developing a contralateral breast cancer (CBC) and distant cancer recurrence, the options for managing a $\mathrm{CBC}$, and a clear recommendation for or against CPM. CPM is never an emergency and is never mandatory; even for patients at the highest risk of $\mathrm{CBC}$, in the absence of disease, close surveillance is always a reasonable alternative to surgery.

\section{CPM and Impact on Cancer Outcomes}

Risk of $C B C$ and Reduction of $C B C$ with $C P M$ Among women with breast cancer, the absolute risk of developing a CBC exceeds that of the general population and is approximately $0.6 \%$ per year in historic series. ${ }^{11}$ Because systemic adjuvant chemotherapy reduces this risk by about $20 \%$, tamoxifen by about $50 \%$, and aromatase inhibitors by about $60 \%$, the contemporary risk of developing a CBC is likely lower at $0.2-0.5 \%$ per year for those undergoing adjuvant therapies. ${ }^{12}$ Survivorship bias must be taken into account when looking at factors associated with $\mathrm{CBC}$ because the only patients who develop a CBC are those who survive their first primary cancer.

Known factors contributing to the risk of developing CBC include individual patient factors (family history, gene mutation status, patient age, etc.) as well as treatment related to the index breast cancer (use of chemotherapy, hormone therapy, etc.). For known BRCA1/2 mutation carriers, studies have shown a 30 $40 \%$ risk of $\mathrm{CBC}$ at 10 years, and the risk appears to continue beyond 10 years. ${ }^{13}$ The $\mathrm{CBC}$ risk for carriers of other genes such as CHEK2, p53, PALB2, ATM, and NBN is less well studied, and at this time there is insufficient evidence to support an increased $\mathrm{CBC}$ risk for these mutations. Early studies of CHEK2 mutation carriers showed an increased risk for $\mathrm{CBC}$, but future studies are warranted to verify this finding. ${ }^{14,15}$ Patients at higher risk for breast cancer, such as those who have undergone mantle radiation for Hodgkin lymphoma, may be at increased risk for $\mathrm{CBC}$, but few studies have verified this. ${ }^{16}$ For patients with a significant family history with no proven gene mutation or in whom genetic testing was not done, the risk of CBC varies by number and degree of the relative(s) affected by breast cancer and the age of the patient. In the WECARE study, the 10-year cumulative risk of breast cancer for a 30-year-old woman with a firstdegree relative is $14.7 \%$ compared to a 50-year-old woman, whose risk is $6.7 \%$ at 10 years. ${ }^{17} \mathrm{CBC}$ risk varies by the hormone receptor status of the primary tumor. In the overview analysis, the risk of CBC was $0.4 \%$ per year for estrogen receptor-positive patients and $0.5 \%$ per year for estrogen receptor-negative patients. ${ }^{18}$ A Surveillance, Epidemiology, and End Results (SEER) study performed nearly 10 years ago showed that CBC risk has been decreasing $3 \%$ per year since 1985 due in part to increased use of hormone therapy. ${ }^{19}$ Annual risks of $\mathrm{CBC}$ are highest in patients younger than 30 years and patients with multiple affected first- and second-degree relatives (annual risk 0.4-1.3\%).

There is strong evidence that CPM reduces the relative risk of cancer in the contralateral breast by 90 to $95 \%$; however, breast cancer risk is not completely eliminated with CPM. The absolute risk of developing cancer on that side after CPM ranges from 0 to $1.5 \%{ }^{20-25}$

Summary Risk of CBC for average-risk women with breast cancer is 0.1 to $0.6 \%$ per year. CBC risk is higher for women diagnosed at a young age, those with a strong family history, and BRCA carriers. 
Impact of CPM on Overall Survival and Disease-Free Survival There are no prospective studies on the impact of CPM on overall survival (OS) and disease-free survival (DFS). In view of this, all published studies comparing OS and DFS for woman undergoing CPM with those not undergoing CPM have to be interpreted with caution, as they are retrospective and may contain known and unknown biases. Multiple retrospective studies have compared OS and DFS in women undergoing CPM compared to those not undergoing CPM. Some have shown a DFS benefit ${ }^{21,24-29}$ and some have shown an OS benefit to CPM. ${ }^{21,27-30}$ However, these studies cannot establish a causal link between CPM and survival. The Cochrane Database, a meta-analysis, and other studies indicate no difference in OS or breast cancer-specific survival and cite selection bias as the cause of superior outcomes in the studies that demonstrated improvement in survival. ${ }^{22,31,32}$ A recent SEER analysis examined CPM's effect not only on all-cause and breast cancer mortality but also on noncancer mortality. ${ }^{33}$ This study showed a greater reduction in noncancer mortality for CPM than for allcause or breast cancer mortality and illustrates how selection bias likely accounts for the survival benefit reported from CPM.

For those patients at the highest $\mathrm{CBC}$ risk, such as $B R C A$ carriers, retrospective studies have shown that patients who underwent CPM had better OS than BRCA carriers who did not undergo CPM. ${ }^{20,34,35}$ Among Hodgkin lymphoma survivors, the increased risk of breast cancer is well documented, but too few patients have developed contralateral disease to make a reliable estimate of either $\mathrm{CBC}$ risk or CPM benefit. ${ }^{36,37}$

Summary CPM does not appear to be associated with a survival benefit, with the possible exception of $B R C A$ carriers.

\section{CPM's Impact on Noncancer Outcomes}

Surgical Risks of CPM (with/without Reconstruction) Complications can be divided into categories based on time (early, intermediate, late) and type (surgical, oncologic, reconstructive). Early complications are dominated by surgical site issues such as tissue/skin flap necrosis, infection, bleeding, and standard surgical complications such as deep-vein thrombosis and anesthesia complications. Because reconstructive complications on the CPM side would not have occurred without the CPM, it is reasonable to consider the complications from the mastectomy and also any reconstructive complications (implant loss, flap loss, unanticipated revisions, etc.) from both the immediate procedure and subsequent procedures required for completion of the reconstruction. Taking these together, complications are estimated to occur in 40-64\% over the entire course of a reconstruction, with an estimate of $52 \%$ of patients having at least one unanticipated surgery in one series. ${ }^{38}$

CPM has been shown to have double the complication rate compared to unilateral mastectomy, regardless of whether reconstruction is performed or not, and complications occur almost equally on the affected and prophylactic sides. ${ }^{39-42}$ CPM increases complications that require return to the operating room, and removal of an implant or significant skin necrosis, as well as more minor complications such as cellulitis, small areas of skin necrosis, or hematomas that do not require a return to the operating room. ${ }^{39}$ Potential comorbidities that may increase the likelihood of complications (such as cardiac/pulmonary comorbidities, obesity, diabetes, smoking, use of steroids or anticoagulants) should be considered when considering the possible harms of CPM and any potential benefits.

Summary CPM doubles the risk of surgical complications.

Oncologic Risks of CPM CPM may negatively affect oncologic outcomes for patients who were never destined to develop a CBC. Surgical complications may delay the onset of adjuvant therapy, or may encourage patients to avoid therapy that would otherwise be recommended, such as radiotherapy. One study has shown that patients undergoing CPM had longer delays to adjuvant therapy then those patients undergoing unilateral mastectomy or lumpectomy. ${ }^{43}$

CPM and Aesthetic Outcome Symmetry is a significant driver for CPM, especially for women with ptotic or large breasts. Satisfaction with breast appearance has been shown to be higher with bilateral mastectomy and implant reconstruction compared to unilateral mastectomy with implant reconstruction. ${ }^{44}$ Regardless of technique, reconstructing both sides at the same time allows for more degrees of freedom and less constraints in reconstructive options, perhaps resulting in better outcomes. When autologous choices are made for reconstruction, CPM also allows for the use of the entire abdominal donor site as opposed to discarding half when a unilateral reconstruction is performed. With advances in reconstructive surgical techniques and options, CPM in patients undergoing mastectomy for their primary tumor may improve symmetry; however, it is important to educate women that symmetry procedures are available that do not require mastectomy and can provide symmetry with potentially fewer surgical and wound complications and preserve sensation. 
CPM has been associated with negative outcomes on quality of life associated with reconstructive surgery. Survey studies of patients who have undergone reconstruction have shown that up to $20-30 \%$ of patients report that outcomes from their reconstruction such as the cosmetic appearance, numbness or tingling, and sexuality were worse than expected. ${ }^{45-48}$ Additionally, a similar proportion of patients report that the number of operations needed to complete their reconstruction was more than expected, and the need for unplanned reoperations was associated with less satisfaction with the procedure. ${ }^{45,49}$ Patients who undergo CPM do rate their satisfaction with their breast appearance higher with reconstruction than those who do not undergo CPM, but physical effects such as pain and sexuality were no different between CPM and non-CPM patients. ${ }^{44,50}$ These factors, along with patient desire to improve overall aesthetic appearance of their reconstruction, should be taken into account when discussing the option of CPM and reconstruction with patients.

Summary Bilateral reconstruction may provide improved cosmetic outcome.

\section{When CPM Should Be Considered or Discouraged}

Average-risk women with unilateral breast cancer do not derive any oncologic benefit from CPM, and thus CPM should be discouraged.

From a risk perspective, CPM should be considered primarily for women at the highest risk for $\mathrm{CBC}$, specifically those women with (1) deleterious mutations of $B R C A 1 / 2$, (2) a greater than $25 \%$ lifetime risk of breast cancer primarily due to family history in the absence of deleterious mutations, or (3) a history of mantle radiation (typically for Hodgkin lymphoma) before age 30.36,37

For patients with a strong family history without a known genetic mutation and patients with other breast cancer risk genes such as $C H E K 2, P A L B 2$, and $C D H 1$, there is insufficient evidence regarding $\mathrm{CBC}$ risk to recommend for or against CPM in these patients, and therefore CPM can be considered.

Symmetry is a significant driver for CPM, especially for those with ptotic or large breasts and unilateral breast malignancy. Plastic surgical consultation is highly recommended whenever mastectomy is required or chosen for management of the index cancer and the patient is interested in reconstruction. This consultation should involve a detailed discussion about what each reconstructive procedure involves, recovery time, the need for additional operations, and the risks associated with the procedure.

Patients with more advanced disease, when timing of adjuvant oncologic therapy is critical and risk of recurrence from the primary tumor greatly outweighs potential risk of $\mathrm{CBC}$, should not undergo CPM. Additionally, patients with comorbidities such as significant cardiac or pulmonary disease, chronic anticoagulation or steroid use, poorly controlled diabetes, poor wound healing, and liver failure should be discouraged from CPM because the surgical risks of the procedure likely outweigh any benefits.

\section{CONCLUSIONS}

CPM should be considered for those at significant risk of $\mathrm{CBC}$

- Documented BRCA1/2 carrier.

- Strong family history, but patient has not undergone genetic testing.

- History of mantle chest radiation before age 30 years.

CPM can be considered for those at lower risk of CBC

- Gene carrier of non-BRCA gene (e.g., CHEK-2, PALB2, p53, $\mathrm{CDH1}$.

- Strong family history, patient $B R C A$ negative, no known BRCA family member.

CPM may be considered for other reasons

- To limit contralateral breast surveillance (dense breasts, failed surveillance, recall fatigue).

- To improve reconstructed breast symmetry.

- To manage risk aversion.

- To manage extreme anxiety. (This may be better managed through psychological support strategies.)

CPM should be discouraged

- Average-risk woman with unilateral breast cancer.

- Women with advanced index cancer (e.g., inflammatory breast cancer, T4 or N3 disease, stage IV disease).

- Women at high risk for surgical complications (e.g., patients with comorbidities: obesity, smoker, diabetes).

- Woman tested BRCA negative with a family of $B R C A$ positive carriers.

- Male breast cancer, including BRCA carriers.

DISCLOSURE The authors declare no conflict of interest.

OPEN ACCESS This article is distributed under the terms of the Creative Commons Attribution 4.0 International License (http:// creativecommons.org/licenses/by/4.0/), which permits unrestricted use, distribution, and reproduction in any medium, provided you give appropriate credit to the original author(s) and the source, provide a link to the Creative Commons license, and indicate if changes were made.

\section{REFERENCES}

1. American Board of Medicine. Choosing Wisely. http://www. choosingwisely.org/. 
2. Brown D, Shao S, Jatoi I, Shriver CD, Zhu K. Trends in use of contralateral prophylactic mastectomy by racial/ethnic group and ER/PR status among patients with breast cancer: a SEER population-based study. Cancer Epidemiol. 2016;42:24-31.

3. Pesce CE, Liederbach E, Czechura T, Winchester DJ, Yao K. Changing surgical trends in young patients with early stage breast cancer, 2003 to 2010: a report from the National Cancer Data Base. J Am Coll Surg. 2014;219:19-28.

4. Steiner CA, Weiss AJ, Barrett ML, Fingar KR, Davis PH. Trends in bilateral and unilateral mastectomies in hospital inpatient and ambulatory settings, 2005-2013. Rockville, MD: Healthcare Cost and Utilization Project. 2015. Statistical Brief 201. http://www. hcup-us.ahrq.gov/reports/statbriefs/sb201-Mastectomies-InpatientOutpatient.pdf

5. NIH Consensus Conference. Treatment of early-stage breast cancer. JAMA. 1991;265:391-5.

6. Golshan M, Cirrincione CT, Sikov WM, et al. Impact of neoadjuvant chemotherapy in stage II-III triple negative breast cancer on eligibility for breast-conserving surgery and breast conservation rates: surgical results from CALGB 40603 (Alliance). Ann Surg. 2015;262:434-9.

7. Killelea BK, Yang VQ, Mougalian S, Horowitz NR, Pasztai L, Chagpar AB, et al. Neoadjuvant chemotherapy for breast cancer increases the rate of breast conservation: results from the National Cancer Database. J Am Coll Surg. 2015;220:1063-9.

8. Silverstein MJ, Savalia N, Khan S, Ryan J. Extreme oncoplasty: breast conservation for patients who need mastectomy. Breast $J$. 2015;21:52-9.

9. Savalia NB, Silverstein MJ. Oncoplastic breast reconstruction: patient selection and surgical techniques. J Surg Oncol. 2016;113:875-82.

10. Smith B, Jiang J, Shih YC, et al. Complication and economic burden of local therapy options for early breast cancer (abstract). Paper presented at: San Antonio Breast Cancer Symposium 2015.

11. Gao X, Fisher SG, Emami B. Risk of second primary cancer in the contralateral breast in women treated for early-stage breast cancer: a population-based study. Int J Radiat Oncol Biol Phys. 2003;56:1038-45.

12. Early Breast Cancer Trialists' Collaborative Group (EBCTCG). Effects of chemotherapy and hormonal therapy for early breast cancer on recurrence and 15-year survival: an overview of the randomised trials. Lancet. 2005;365:1687-17.

13. Metcalfe K, Lynch HT, Ghadirian P, et al. Contralateral breast cancer in BRCA1 and BRCA2 mutation carriers. J Clin Oncol. 2004;22:2328-35.

14. Weischer M, Nordestgaard BG, Pharoah P, et al. CHEK2*1100delC heterozygosity in women with breast cancer associated with early death, breast cancer-specific death, and increased risk of a second breast cancer. J Clin Oncol. 2012;30:4308-16.

15. Kriege M, Hollestelle A, Jager A, et al. Survival and contralateral breast cancer in $C H E K 21100$ delC breast cancer patients: impact of adjuvant chemotherapy. Br J Cancer. 2014;111:1004-13.

16. Elkin EB, Klem ML, Gonzales AM, et al. Characteristics and outcomes of breast cancer in women with and without a history of radiation for Hodgkin's lymphoma: a multi-institutional, matched cohort study. J Clin Oncol. 2011;29:2466-73.

17. Reiner AS, John EM, Brooks JD, et al. Risk of asynchronous contralateral breast cancer in noncarriers of $B R C A 1$ and $B R C A 2$ mutations with a family history of breast cancer: a report from the Women's Environmental Cancer and Radiation Epidemiology Study. J Clin Oncol. 2013;31:433-9.

18. Early Breast Cancer Trialists' Collaborative Group (EBCTCG), Davies C, Godwin J, Gray R, et al. Relevance of breast cancer hormone receptors and other factors to the efficacy of adjuvant tamoxifen: patient-level meta-analysis of randomised trials. Lancet. 2011;378:771-84.
19. Nichols HB, Berrington de Gonzalez A, Lacey JV Jr, Rosenberg PS, Anderson WF. Declining incidence of contralateral breast cancer in the United States from 1975 to 2006. J Clin Oncol. 2011;29:1564-9.

20. Metcalfe K, Gershman S, Ghadirian P, et al. Contralateral mastectomy and survival after breast cancer in carriers of $B R C A 1$ and BRCA2 mutations: retrospective analysis. BMJ. 2014;348:g226.

21. Herrinton LJ, Barlow WE, Yu O, et al. Efficacy of prophylactic mastectomy in women with unilateral breast cancer: a Cancer Research Network project. J Clin Oncol. 2005;23:4275-86.

22. van Sprundel TC, Schmidt MK, Rookus MA, et al. Risk reduction of contralateral breast cancer and survival after contralateral prophylactic mastectomy in $B R C A 1$ or $B R C A 2$ mutation carriers. Br J Cancer. 2005;93:287-92.

23. McDonnell SK, Schaid DJ, Myers JL, et al. Efficacy of contralateral prophylactic mastectomy in women with a personal and family history of breast cancer. J Clin Oncol. 2001;19:3938-43.

24. Boughey JC, Hoskin TL, Degnim AC, et al. Contralateral prophylactic mastectomy is associated with a survival advantage in high-risk women with a personal history of breast cancer. Ann Surg Oncol. 2010;17:2702-9.

25. Peralta EA, Ellenhorn JD, Wagman LD, Dagis A, Andersen JS, Chu DZ. Contralateral prophylactic mastectomy improves the outcome of selected patients undergoing mastectomy for breast cancer. Am J Surg. 2000;180:439-45.

26. Bedrosian I, Hu CY, Chang GJ. Population-based study of contralateral prophylactic mastectomy and survival outcomes of breast cancer patients. J Natl Cancer Inst. 2010;102:401-9.

27. Brewster AM, Bedrosian I, Parker PA, et al. Association between contralateral prophylactic mastectomy and breast cancer outcomes by hormone receptor status. Cancer. 2012;118:5637-43.

28. Kruper L, Kauffmann RM, Smith DD, Nelson RA. Survival analysis of contralateral prophylactic mastectomy: a question of selection bias. Ann Surg Oncol. 2014;21:3448-56.

29. Lee JS, Grant CS, Donohue JH, Crotty TB, Harmsen WS, Ilstrup DM. Arguments against routine contralateral mastectomy or undirected biopsy for invasive lobular breast cancer. Surgery. 1995;118:640-7.

30. Yao K, Stewart AK, Winchester DJ, Winchester DP. Trends in contralateral prophylactic mastectomy for unilateral cancer: a report from the National Cancer Data Base, 1998-2007. Ann Surg Oncol. 2010;17:2554-62.

31. Lostumbo L, Carbine NE, Wallace J. Prophylactic mastectomy for the prevention of breast cancer. Cochrane Database Syst Rev. 2010;11:CD002748.

32. Fayanju OM, Stoll CR, Fowler S, Colditz GA, Margenthaler JA. Contralateral prophylactic mastectomy after unilateral breast cancer: a systematic review and meta-analysis. Ann Surg. 2014; 260:1000-10.

33. Jatoi I, Parsons HM. Contralateral prophylactic mastectomy and its association with reduced mortality: evidence for selection bias. Breast Cancer Res Treat. 2014;148:389-96.

34. Heemskerk-Gerritsen BA, Rookus MA, Aalfs CM, et al. Improved overall survival after contralateral risk-reducing mastectomy in BRCA1/2 mutation carriers with a history of unilateral breast cancer: a prospective analysis. Int J Cancer. 2015;136: 668-77.

35. Evans DG, Ingham SL, Baildam A, Ross GL, Lalloo F, Buchan I, et al. Contralateral mastectomy improves survival in women with BRCA1/2-associated breast cancer. Breast Cancer Res Treat. 2013;140:135-42.

36. Swerdlow AJ, Cooke R, Bates A, et al. Breast cancer risk after supradiaphragmatic radiotherapy for Hodgkin's lymphoma in England and Wales: a National Cohort Study. J Clin Oncol. 2012; $30: 2745-52$. 
37. Schaapveld M, Aleman BM, van Eggermond AM, et al. Second cancer risk up to 40 years after treatment for Hodgkin's lymphoma. N Engl J Med. 2015;373:2499-511.

38. Zion SM, Slezak JM, Sellers TA, et al. Reoperations after prophylactic mastectomy with or without implant reconstruction. Cancer. 2003;98:2152-60.

39. Miller ME, Czechura T, Martz B, et al. Operative risks associated with contralateral prophylactic mastectomy: a single institution experience. Ann Surg Oncol. 2013;20:4113-20.

40. Silva AK, Lapin B, Yao KA, Song DH, Sisco M. The effect of contralateral prophylactic mastectomy on perioperative complications in women undergoing immediate breast reconstruction: a NSQIP analysis. Ann Surg Oncol. 2015;22:3474-80.

41. Osman F, Saleh F, Jackson TD, Corrigan MA, Cil T. Increased postoperative complications in bilateral mastectomy patients compared to unilateral mastectomy: an analysis of the NSQIP database. Ann Surg Oncol. 2013;20:3212-7.

42. Crosby MA, Garvey PB, Selber JC, et al. Reconstructive outcomes in patients undergoing contralateral prophylactic mastectomy. Plast Reconstr Surg. 2011;128:1025-33.

43. Sharpe SM, Liederbach E, Czechura T, Pesce C, Winchester DJ, Yao K. Impact of bilateral versus unilateral mastectomy on short term outcomes and adjuvant therapy, 2003-2010: a report from the National Cancer Data Base. Ann Surg Oncol. 2014;21:29207.

44. Koslow S, Pharmer LA, Scott AM, Stempel M, Morrow M, Pusic $\mathrm{AL}$, et al. Long-term patient-reported satisfaction after contralateral prophylactic mastectomy and implant reconstruction. Ann Surg Oncol. 2013;20:3422-9.

45. Rosenberg SM, Tracy MS, Meyer ME, et al. Perceptions, knowledge, and satisfaction with contralateral prophylactic mastectomy among young women with breast cancer: a crosssectional survey. Ann Intern Med. 2013;159:373-81.

46. Frost MH, Schaid DJ, Sellers TA, et al. Long-term satisfaction and psychological and social function following bilateral prophylactic mastectomy. JAMA. 2000;284:319-24.

47. Frost MH, Hoskin TL, Hartmann LC, Degnim AC, Johnson JL, Boughey JC. Contralateral prophylactic mastectomy: long-term consistency of satisfaction and adverse effects and the significance of informed decision-making, quality of life, and personality traits. Ann Surg Oncol. 2011;18:3110-6.

48. Altschuler A, Nekhlyudov L, Rolnick SJ, et al. Positive, negative, and disparate-women's differing long-term psychosocial experiences of bilateral or contralateral prophylactic mastectomy. Breast J. 2008;14:25-32.

49. Boughey JC, Hoskin TL, Hartmann LC, Johnson JL, Jacobson SR, Degnim AC, et al. Impact of reconstruction and reoperation on long-term patient-reported satisfaction after contralateral prophylactic mastectomy. Ann Surg Oncol. 2015;22:401-8.

50. Hwang ES, Locklear TD, Rushing CN, Samsa G, Abernethy AP, Hyslop T, et al. Patient-reported outcomes after choice for contralateral prophylactic mastectomy. J Clin Oncol. 2016;34:151827. 